\title{
KIDNEY FUNCTION IN PNEUMONIA
}

\author{
By JOHN F. McINTOSH AND HOBART A. REIMANN \\ (From The Hospital of the Rockefeller Institute for Medical Research)
}

(Received for publication May 29, 1926)

\section{INTRODUCTION}

Studies of the changes which occur in kidney function during the course of lobar pneumonia have been made by several investigators. The results which they have obtained show little uniformity, and the conclusions arrived at are quite at variance. Tileston and Comfort (1) studied 14 cases of lobar pneumonia and found an elevation in the blood urea during the febrile stage. They made 8 phenolsulphonphthalein tests, and found a diminution in excretion in 3 instances. Schwartz and McGill (2) in a series of 20 cases, obtained very similar findings. Longcope and Peters (3) studied 4 cases of pneumonia incidental to their study of renal function in serum disease. The phenolsulphonphthalein excretion was below normal in only one of their 6 determinations, and the blood urea was normal in all instances. They compared the urea in the urine with the urea in the blood by means of McLean's index, and found normal values in all their determinations. Bookman (4), on the other hand, found a diminished 'phthalein output in 5 of his 6 cases of pneumonia, and considered that without other signs of nephritis, most cases showed distinctly impaired function. The blood urea showed no striking change in his series. Lewis (5) investigated 8 cases of lobar pneumonia in his study of the clinical value of Ambard's "coefficient of urea excretion." He found a well marked increase in the phenolsulphonphthalein excretion, the average for 2 hours being 70.5 per cent, compared with 60.2 per cent in his series of 28 normal cases. The values given for the blood urea nitrogen were all normal, but the output of urea in the urine was higher than one would expect in a normal individual. Lewis points out that "any kidney capable of raising the concentration of the urinary urea to a level 80 times that in the 
blood can scarcely be called a hyperpermeable organ," but that "the increased rate of output indicates an increased functional ability of the kidney."

Frothingham (6) failed to find a general increase in phenolsulphonphthalein excretion. Of 15 determinations done on 10 cases, only one (which was done during the febrile stage) showed an increased output ( 83 per cent), while decreased outputs were obtained twice. Five of the cases showed a McLean index higher than normal during the febrile stage, which returned to normal limits during convalescence in the four instances in which the test was repeated. The index was subnormal in 3 determinations, once during the disease, and twice after the patients were afebrile. This author concludes that since the increase in the index was not associated with an increase in phenolsulphonphthalein a hyperactivity of the kidney does not occur during fever. He also considered that the tests failed to show consistent evidence of impaired renal function during the course of the disease.

Of the six authors, therefore, three emphasize the finding of impairment of kidney function, two emphasize the absence of impairment, and one emphasizes the occurrence of hyperfunction during the course of lobar pneumonia. It seemed to us, therefore, that a series of observations, repeated at intervals during the course of the disease, might throw some light on the cause of such discordant results. The urea concentration index, recently described by Van Slyke, Linder, Hiller, Leiter and McIntosh (8), by means of which the concentrating power of the kidney for urea under standard conditions is estimated, seemed to be a convenient method for the study. It also seemed to us that such a study would be necessary before this test could be used as a diagnostic measure in suspected cases of nephritis, in which a febrile disease, such as pneumonia, was present, at the time of the test, or shortly antecedent to it.

\section{METHODS}

In the material presented, the phenolsulphonphthalein was given intravenously, and the specimens collected at the end of one hour, and 2 hours, when this was possible. This object was not always achieved on account of the inability of the patients to void at the 
proper time. Such results were discarded. It seemed to us that in view of the frequency of difficulty in voiding, phenolsulphonphthalein tests are not wholly reliable in such cases, unless catheterization is carried out. The urea concentration index is open to the same objection, but in this instance the error can be minimized by lengthening the period of urine collection. In this study, all urine collections which were open to suspicion of being incomplete were discarded. The patients were given $150 \mathrm{cc}$. of water fifteen minutes before the first voiding, and urine collections were made over a period of 2 hours as a standard procedure. The urine and blood urea was determined by the urease method of Van Slyke and Cullen (7) except in a few urine urea determinations, which were made by a gasometric method which will shortly be described by Van Slyke. The significance of the urea concentration index may be described by stating that it represents the number of times the kidneys concentrate urea in excreting it from the blood into the urine, when the urine volume output is at the average normal rate of $1 \mathrm{cc}$. per minute, or $1 \mathrm{cc}$. per hour per kilo of body weight. Values of 35 to 80 for the index are regarded as being normal, and 55 per cent as the lower limit of normal for phenolsulphonphthalein determination.

\section{RESULTS}

In all, 13 cases were studied. The results are summarized in table 1. The most characteristic finding is to be noted in cases 1,2 , and 3 . These show a normal index early in the disease, followed by a marked increase, which usually occurred before the crisis, and lasted in one case as long as seven days after it. The index subsequently returned to normal. In cases 4,5 , and 6 the same supra-normal indices were observed during the febrile period, and in each case, a return to normal occurred after the crisis. The phenolsulphonphthalein return showed the same supra-normal phase, and a good parallelism can be observed between it and the index in cases 1, 2, 3, and 4 .

None of the other cases showed definitely supra-normal indices. Nevertheless, the same tendency to hyperfunction can be observed in several of them. Case 9 showed a series of three indices between the fourth and the tenth day, which were probably considerably above his individual normal level. This case, as well as cases 8 and 12 , also showed an increased output of phenolsulphonphthalein. 
TABLE 1

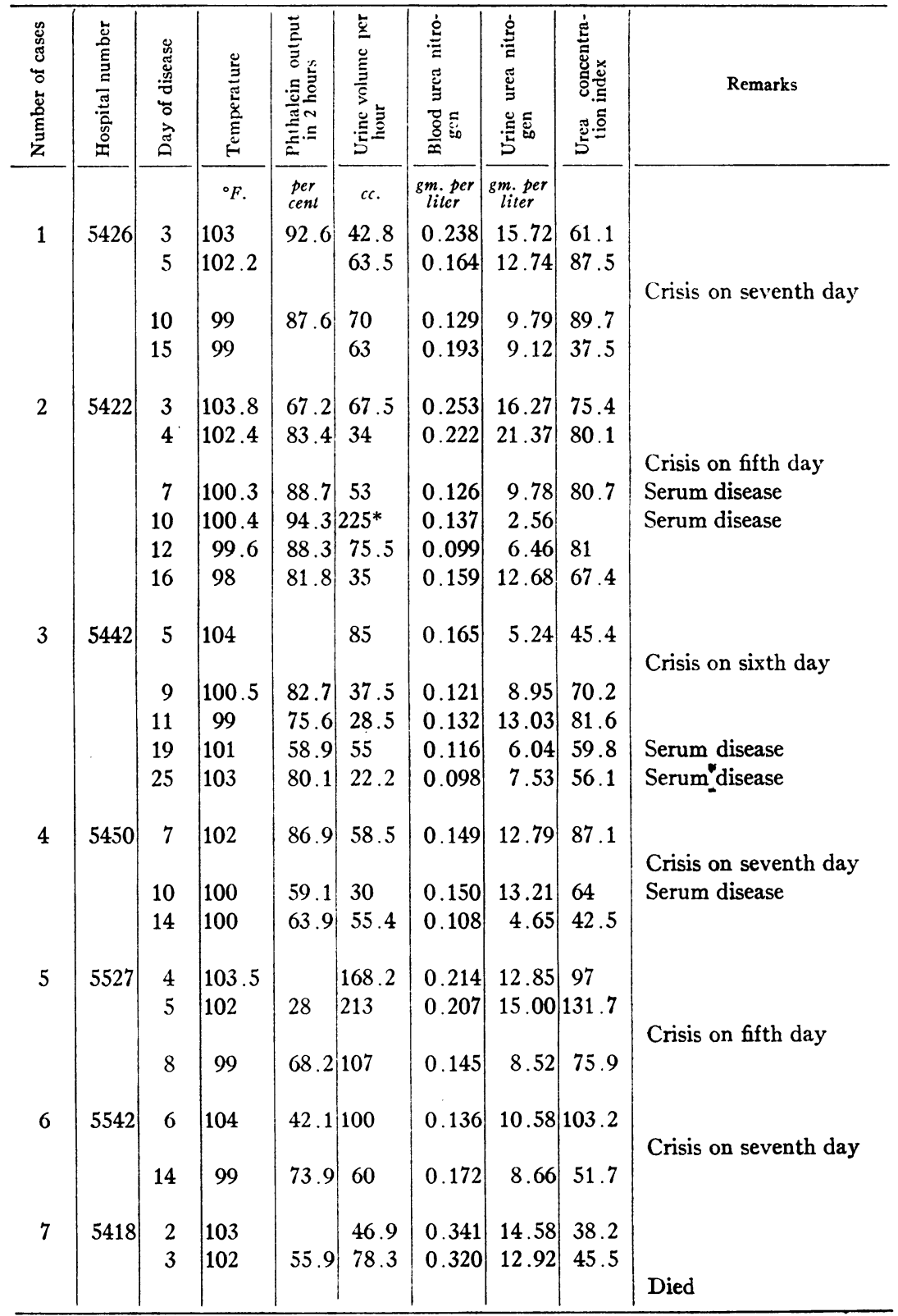

* This urine is above the "augmentation limit" and the index cannot be calculated. 
JOHN F. MCINTOSH AND HOBART A. REIMANN

TABLE 1-Concluded

\begin{tabular}{|c|c|c|c|c|c|c|c|c|c|}
\hline 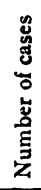 & 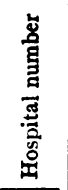 & 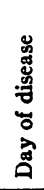 & 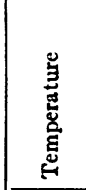 & 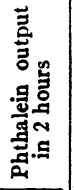 & 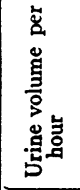 & 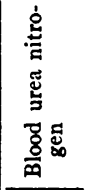 & 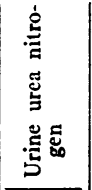 & 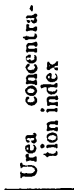 & Remarks \\
\hline \multirow{6}{*}{8} & & & ${ }^{\circ} F$. & $\begin{array}{c}\text { per } \\
\text { cent }\end{array}$ & $c c$. & $\begin{array}{l}\text { gm.per } \\
\text { liler }\end{array}$ & $\begin{array}{c}\text { gm.per } \\
\text { liter }\end{array}$ & & \multirow{7}{*}{ Crisis on sixth day } \\
\hline & 5427 & 3 & 103 & 48.7 & 95 & 0.164 & 6.24 & 47.2 & \\
\hline & & 5 & 103.2 & 84.4 & 80 & 0.381 & 12.09 & 36.1 & \\
\hline & & 9 & 99.2 & 92.5 & 65 & 0.263 & 14.64 & 57.1 & \\
\hline & & 15 & 99 & 83.7 & 67 & 0.243 & 8.40 & 36 & \\
\hline & & 18 & 99 & 66.1 & 85 & 0.156 & 4.92 & 37 & \\
\hline \multirow[t]{5}{*}{9} & 5436 & 2 & 99.5 & & 77.5 & 0.572 & 11.07 & 21.5 & \\
\hline & & 4 & 101 & 65.9 & 48 & 0.229 & 17.94 & 68.5 & Crisis on second day \\
\hline & & 6 & 100.6 & 49.1 & 47.5 & 0.156 & 12.33 & 68.8 & Mild serum disease \\
\hline & & 10 & 98 & 79.4 & 46.5 & 0.176 & 13.83 & 67.6 & \\
\hline & & 12 & 98 & & 60 & 0.162 & 8.58 & 51.8 & \\
\hline \multirow[t]{4}{*}{10} & 5607 & 4 & 103.5 & 32.8 & 100 & 0.173 & 6.95 & 51.8 & \multirow{4}{*}{ Crisis on ninth day } \\
\hline & & 9 & 102 & 50.3 & 86 & 0.405 & 5.36 & 15.8 & \\
\hline & & 14 & 99 & 59 & 71 & $\dot{0} .240$ & 7.27 & 32.9 & \\
\hline & & 22 & 99 & 60.1 & 28.6 & 0.152 & 7.30 & 33.1 & \\
\hline \multirow[t]{3}{*}{11} & 5602 & 4 & 103.5 & & 95.6 & 0.279 & 10.84 & 44.6 & \multirow{3}{*}{ Crisis on ninth day } \\
\hline & & 7 & 102 & & 80 & 0.303 & 7.37 & 25.5 & \\
\hline & & 12 & 100 & 75 & 50 & 0.220 & 16.80 & 63.4 & \\
\hline \multirow[t]{3}{*}{12} & 5661 & 4 & 103 & 84.2 & 62.5 & 0.332 & 12.88 & 39.7 & \multirow[b]{2}{*}{ Crisis on fourth day } \\
\hline & & 8 & 99 & 87.7 & 42 & 0.209 & 1491 & 598 & \\
\hline & & 11 & 99.6 & 75.2 & 47.5 & 0.212 & 11.98 & 50.5 & \multirow{4}{*}{ Lysis on fourth day } \\
\hline \multirow[t]{3}{*}{13} & 5662 & 2 & 102 & 60.6 & 29 & 0.185 & 7.89 & 31.1 & \\
\hline & & 6 & 101 & 29.5 & 13 & 0127 & 867 & 333 & \\
\hline & & 9 & 100 & 69.4 & 29 & 0.110 & 6.39 & 42.4 & \\
\hline
\end{tabular}

On the other hand, 4 cases were observed which showed a moderate decrease in the index of concentration. Cases 9 and 10 showed such a result on the day of their crises; in case 9, this was followed by a 
relative increase in the index, whereas in case 10 , the index failed to reach normal values in subsequent tests. In case 11, there was one subnormal index before the crisis occurred, and in case 13 one sub-

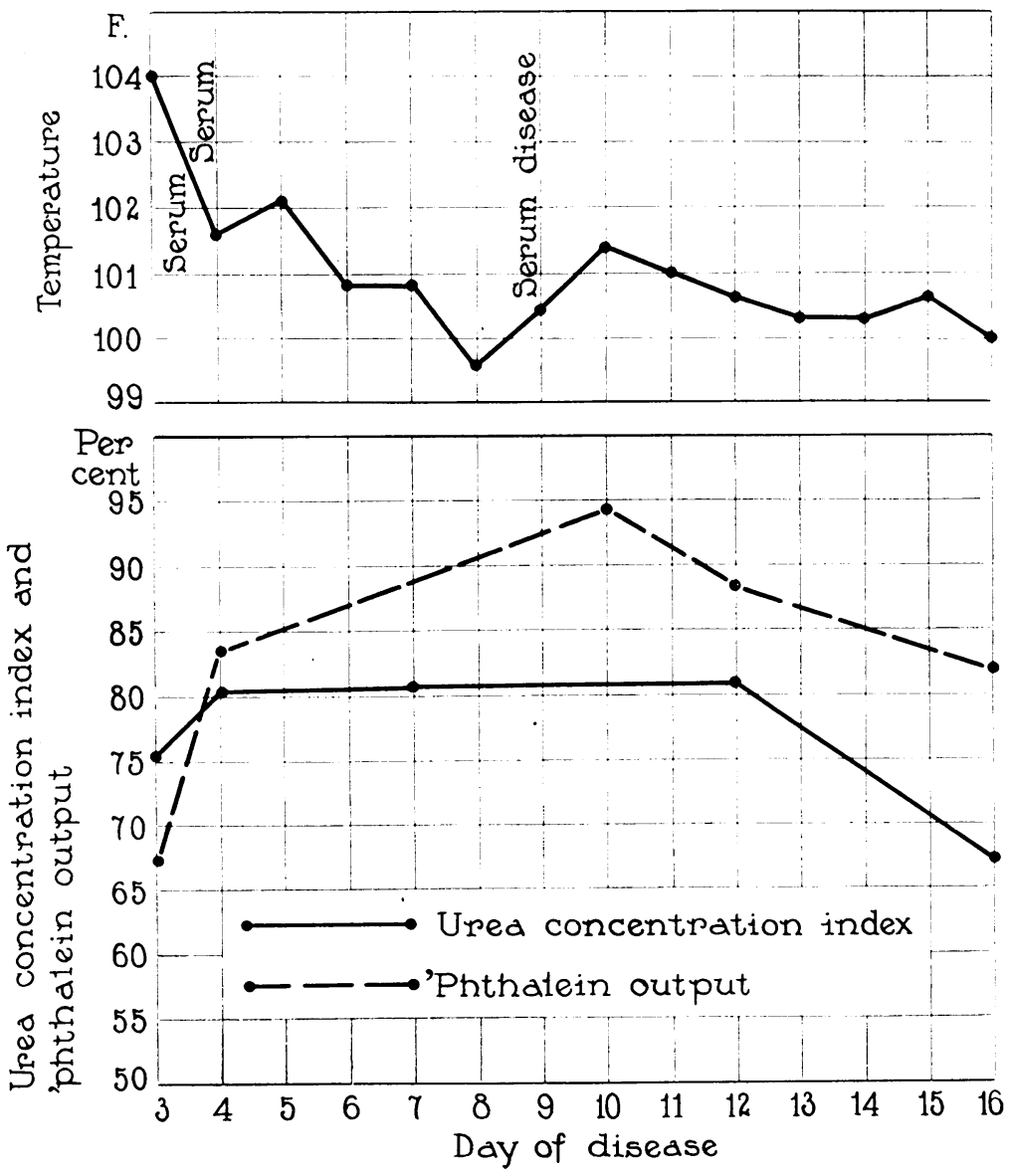

Fig. 1. Case 2. Illustrating Phase of Renal Hyperfunction after Lobar Pneumonia

normal value before and one after the crisis. Both cases gave normal tests at a later stage of convalescence.

Definitely subnormal phenolsulphonpththalein returns are to be served in cases 5, 6, 8, 10, and 13, one such result being noted in each 
case. These individual determinations are not in agreement either with the other phenolsulphonphthalein tests in the same patients, nor with the index found on the same day. One feels inclined to minimize the value of these determinations as a proof of decreased kidney function in these cases. On the whole, however, a moderately good agreement is to be observed between the phenolsulphonphthalein and the index, considering the fact that catheterization was not resorted to in order to obtain complete urine collections.

There are two factors which affect the blood urea level which deserve comment. The increased protein catabolism of the disease tends to raise the blood urea, and values of over 0.3 grams of urea $\mathrm{N}$ per liter are not unusual, even with perfectly normal kidney function. On the other hand, the hyperfunctioning kidneys tend to neutralize this tendency, and when hyperfunction occurs, the blood urea tends to be lower than when it does not occur.

Whether definite anatomical changes occur in the kidney, with which the increase or decrease in functional ability might be correlated, we are unable to state. Albuminuria of slight or moderate degree was present in all the cases during the febrile stage, and it seems reasonable to suppose that some degree of cloudy swelling of the renal epithelium might have been found. None of the cases had any history or clinical findings suggestive of coexistent nephritis.

The cases have been reviewed to observe whether the type of pneumococcus responsible for the pneumonia bore any relation to the changes found in kidney function. No such relation between type of infecting organism and the functional changes is to be observed. Six of the cases were diagnosed as Type I, and of these, 5 received antipneumococcus serum. Subsequently, large doses of neochincophan were given to 4 of them. Four of the cases developed serum disease, manifested by urticaria. None of these incidents seem to have influenced kidney function in any way.

\section{CONCLUSIONS}

1. During the course of lobar pneumonia, the kidneys frequently show a period of increased functional ability. This period usually begins before the crisis, and lasts until several days after it. In a series of 13 cases, the hyperfunction was shown by an increased urea 
concentration index in 6 cases, by an increased phenolsulphonphthalein output in 7 cases, and by one or the other test in 9 cases.

2. A moderate depression of kidney function was observed in 4 cases; this depression was found sometimes before, and sometimes after the crisis.

3. Serious impairment of kidney function during pneumonia was not encountered in this group of cases.

\section{BIBLIOGRAPHY}

1. Tileston, W.. and Comfort, C. W., Jr.: Arch. Int. Med., 1914, xiv, 620. The Total Non-protein Nitrogen and the Urea of the Blood in Health and in Disease, as Estimated by Folin's Methods.

2. Schwartz, H., and McGill, C.: Arch. Int. Med., 1916, xvii, 42. Blood Urea Determinations in 211 Cases.

3. Rackemann, F., Longcope, W. T., and Peters, J. P.: Arch. Int. Med., 1916, xviii, 496. The Excretion of Chlorids and Water and the Renal Function in Serum Disease.

4. Bookman, A.: Arch. Int. Med., 1917, xx, 112. A Study of Renal Function in Patients Convalescing from Acute Fevers.

5. Lewis, D. S.: Arch. Int. Med., 1917, xix, 1. The Clinical Value of Ambard's Coefficient of Urea Excretion.

6. Frothingham, C.: Arch. Int. Med., 1918, xxii, 74. Studies on Renal Function During and Immediately Following Some of the Acute Infectious Diseases.

7. Van Slyke, D. D., and Cullen, G. E.: Jour. Biol. Chem., 1914, xix, 211. A Permanent Preparation of Urease, and Its Use in the Determination of Urea.

8. Van Slyke, D. D., Linder, G. C., Hiller, A., Leiter, L., and McIntosh, J. F.: Jour. Clin. Invest., 1926, ii, 255. The Excretion of Ammonia and Titratable Acid in Nephritis. 